\title{
Ventilation or dignified death for patients with high tetraplegia
}

\author{
B P GARDNER, F THEOCLEOUS, J W H WATT, K R KRISHNAN
}

\begin{abstract}
The case histories of the 37 patients of the Mersey Regional Spinal Injuries Centre who were artificially ventilated between 1968 and 1984 were reviewed. The patients and caring relatives were interviewed separately to determine their views. Of 21 patients who were still alive, 18 said that they would wish to be temporarily ventilated again if the need arose, two were undecided, and one said that she would wish to be allowed to die. Sixteen caring relatives said that they were glad that the decision to ventilate had been taken. Those who were not glad were all young mothers. The outcome from any combination of factors that existed before injury could not be predicted except that most patients over age 59 fared badly.

Patients with spinal cord damage should be artificially ventilated if required, provided that this can be carried out well and that total emotional, educational, and physical support can be provided and maintained. Whether or not scarce resources should be deployed in this manner requires discussion.
\end{abstract}

\section{Introduction}

Patients with spinal cord injuries who require artificial ventilation can be either successfully weaned or enabled to live in the community while still on the ventilator. ${ }^{1.5}$ Many clinicians, however, consider that such patients should not be ventilated but allowed to die instead because the patient would be better dead, the relatives, on whose shoulders the burden of care would fall, would suffer excessively, and the limited resources of spinal injuries centres might be better deployed. We have investigated these aspects.

\section{Patients and methods}

The case histories of all 37 patients who were treated between 1968 and 1984 at this centre and were artificially ventilated were reviewed. Patients and their nearest caring relatives were interviewed separately by BPG. The relatives who were questioned had the closest physical, psychological, emotional, and social bonds with the patients either at the time of the initial admission, for those patients who died before leaving hospital, or at the time of this study, for those patients who were still alive when the survey was conducted. To reduce potential emotional trauma, especially for relatives of patients who had died, interviews were usually conducted in the homes of

\footnotetext{
Mersey Regional Spinal Injuries Centre, Promenade Hospital, Southport PR9 OHY

B P GARDNER, MRCP, FRCS, senior registrar in spinal injuries F THEOCLEOUS, MB, BS, senior house officer

J W H WATT, MD, FFARCS, consultant anaesthetist

K R KRISHNAN, MB, FRCSED, consultant in charge

Correspondence to: Mr Gardner.
}

the patients or relatives. To ensure authenticity, respondents were requested to substantiate each reply. The study was carried out in 1984. Data were stored and analysed using a DBASE 11 database file in a Sirius computer.

\section{Results}

Twenty one patients were alive at the time of the study; 18 of these had gone home and three were preparing to go home. Sixteen patients had died, eight while on the ventilator, five after coming off the ventilator but still in hospital, and three at home. No patient had been discharged home on a ventilator. Table I gives the age of the patients at the time of injury. The average age was 39 years. The duration of survival of those who were still alive ranged from one to 15 years, mean $5 \cdot 4$ years.

\begin{tabular}{cc} 
TABLE I-Ages of patients at injury \\
\hline Age (years) & No of patients \\
\hline $0-9$ & 0 \\
$10-19$ & 5 \\
$20-29$ & 8 \\
$30-39$ & 5 \\
$40-49$ & 7 \\
$50-59$ & 5 \\
$60-69$ & 6 \\
$69+$ & 1 \\
\hline
\end{tabular}

Patients with spinal injuries have been treated at this centre since 1947. Figure 1 shows the year that the injury occurred for those who were ventilated. Figure 2 shows the initial neurological level of those who were ventilated. No patient had any appreciable neurological recovery. At no stage did any patient suffer brain damage sufficient to cause a clinically evident intellectual or personality change. Figure 3 shows on which day after the injury ventilation was started.

Table II gives the views of the patients who had received ventilation. Those who were glad to be alive said that being alive was worth while because there was so much to see and learn in their families and in the world in

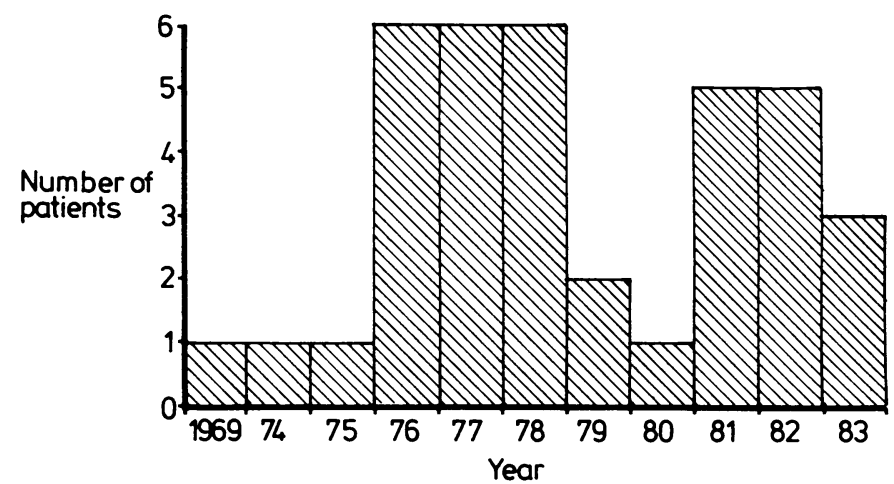

FIG 1-Year that spinal injury occurred. 


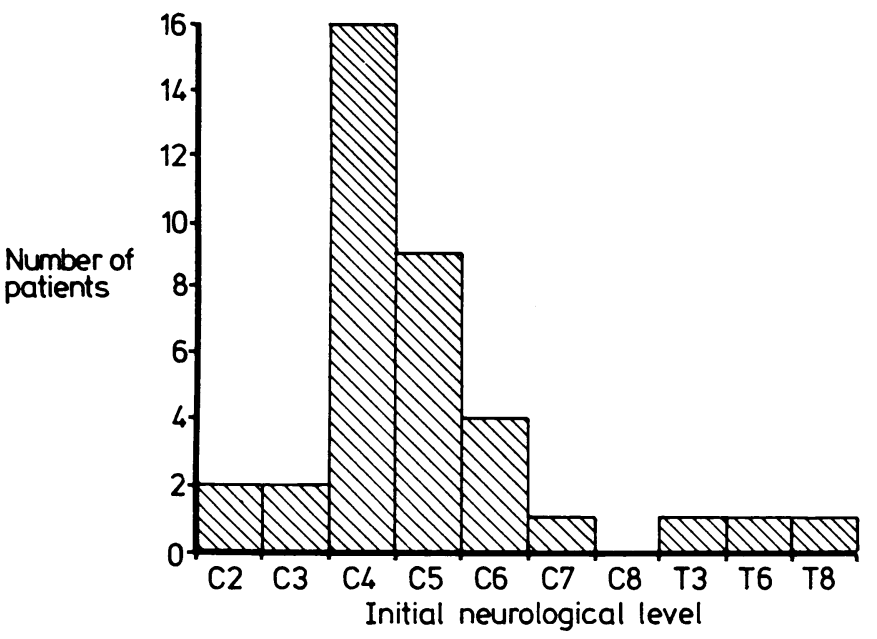

FIG 2-Neurological level before artificial ventilation was started.

general and that there was always hope for the future. Six of the seven who were undecided said that they would definitely wish to have further ventilation if the need arose. The patient who was not glad that she had had ventilation had recently been separated from her husband. Her mother was certain that her daughter's view would soon alter.

Table III gives the views of the caring relatives. Those who were glad that their relative had received ventilation stated that any life was better than none, that family ties were strengthened, that the patient benefited from seeing the family, and that they themselves had gained by becoming more patient and understanding. They were surprised at how much they could achieve and how in time they came to accept their circumstances. Some, however, expressed grave anxieties for the time when they would no longer be able to cope and stated that they hoped their paralysed relative would die before this arose. Many also volunteered the information that their replies would have been different if the relative had suffered brain damage.

TABLE II-Views of the patients

\begin{tabular}{lcccc}
\hline \multicolumn{1}{c}{ Question } & Yes & No & Undecided \\
\hline $\begin{array}{l}\text { Are you glad that you are alive? } \\
\text { If the need arose for further temporary ventilation } \\
\text { would you prefer to be allowed to die? }\end{array}$ & 13 & 1 & 7 \\
$\begin{array}{l}\text { Would it have been better for your family if you had } \\
\text { been allowed to die? }\end{array}$ & 1 & 18 & 2 \\
$\begin{array}{l}\text { Are there any circumstances where a patient should } \\
\text { be allowed to die? }\end{array}$ & 5 & 15 & 1 \\
$\begin{array}{l}\text { Should the doctor alone make the decision regarding } \\
\text { ventilation? }\end{array}$ & 4 & 15 & 2
\end{tabular}

The nine relatives who were not glad that ventilation had been carried out fell into three groups. Firstly, those whose relative had died while on the ventilator considered that everyone had suffered in vain. Secondly, those whose paralysed relative was aged stated that the patient would never recover from the loss of independence. Thirdly, young wives with young children who said that their own loss of dignity, independence, and lifestyle, coupled with the inevitable deprivation of the children, outweighed any benefits accrued by the patient, especially when the support of family and friends drifted away.

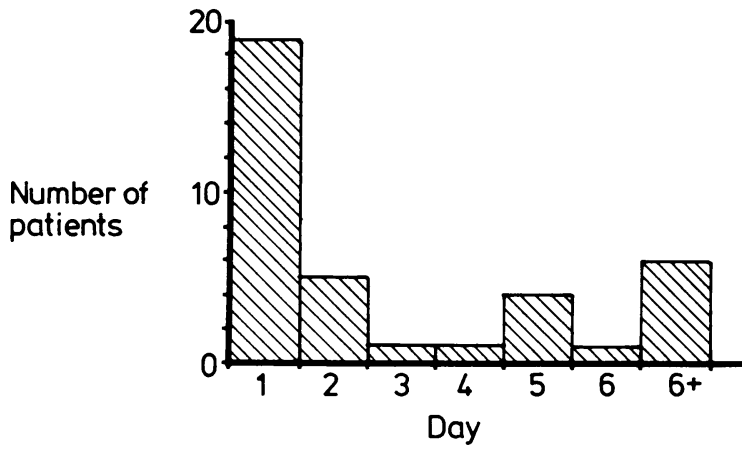

FIG 3-The day after the injury on which ventilation was started.

Patients spent a total of 2159 ventilator days and 14369 ventilator independent days in hospital, including readmission, and a total of 28068 days at home. If it is assumed that ventilated patients require an additional six nursing and three physiotherapy hours each day, this represents a resource diversion over 10 years of 12.5 physiotherapy hours and 25 nursing hours each week.

Poor outcome was defined as the patient dying while still on the ventilator, the patient regretting having received ventilation, or the relatives not being glad that the patient was ventilated. Sixteen patients fell into this category. We correlated combinations of factors that existed before injury with outcome but were unable to show any single factor or combination of factors that were invariably associated with poor outcome.

Parameters of no prognostic value in predicting outcome included sex socioeconomic class, and previous social behaviour. Personality traits before the injury were of limited prognostic value. Some relatives stated that the patient had become more tolerant, understanding, and outgoing. The initial neurological level was only of slight value in predicting outcome. Some patients with high lesions fared particularly well. Poor outcome occurred more often in patients over 59: of seven patients, three died while on the ventilator and two others had caring relatives who were not glad that the decision to ventilate had been taken. The outcome for the other two patients, however, was among the best for all patients in the series.

Four of the six caring relatives who were young wives with young children considered that both they and their husbands would have been better served

\begin{tabular}{|c|c|c|c|c|c|c|c|c|c|c|c|c|c|c|}
\hline \multirow[b]{2}{*}{ Question } & \multicolumn{4}{|c|}{$\begin{array}{l}\text { Relatives of patients } \\
\text { who are alive }\end{array}$} & \multicolumn{3}{|c|}{$\begin{array}{l}\text { Relatives of patients } \\
\text { who died after } \\
\text { discharge home }\end{array}$} & \multicolumn{3}{|c|}{$\begin{array}{l}\text { Relatives of patients } \\
\text { who died in hospital } \\
\text { during initial admission } \\
\text { after being weaned }\end{array}$} & \multicolumn{4}{|c|}{$\begin{array}{c}\text { Relatives of patients } \\
\text { who died in hospital } \\
\text { during initial admission while } \\
\text { still being ventilated }\end{array}$} \\
\hline & Yes & No & Undecided & Unknown & Yes & No & Unknown & Yes & No & Undecided & Yes & No & Undecided & Unknown \\
\hline $\begin{array}{l}\text { Are you glad your relative was kept } \\
\text { alive by ventilation rather than being } \\
\text { allowed to die? } \\
\text { Would your relative have been better off }\end{array}$ & 16 & 4 & 0 & 1 & 2 & 1 & 0 & 3 & 2 & 0 & 4 & 3 & 0 & 1 \\
\hline & 4 & 15 & 1 & 1 & 1 & 2 & 0 & 1 & 3 & 1 & 4 & 2 & 1 & 1 \\
\hline $\begin{array}{l}\text { your relative had been allowed to die? } \\
\text { Overall, have the patient's children or sibs }\end{array}$ & 7 & 13 & 0 & 1 & 0 & 3 & 0 & 0 & 3 & 2 & 4 & 1 & 2 & 1 \\
\hline $\begin{array}{l}\text { suffered more than they have gained? } \\
\text { Have the patient's children or sibs }\end{array}$ & 8 & 7 & 1 & & & 2 & & 1 & & & 1 & 1 & & \\
\hline $\begin{array}{l}\text { been neglected in any way? } \\
\text { Are there any circumstances where }\end{array}$ & 4 & 12 & & & 1 & & 1 & 1 & & & & 2 & & \\
\hline $\begin{array}{l}\text { a patient should be allowed to die? } \\
\text { Should the doctor alone make the }\end{array}$ & 19 & 1 & 0 & 1 & 3 & 0 & 0 & 4 & 1 & 0 & 7 & 0 & 0 & 1 \\
\hline $\begin{array}{l}\text { decision regarding ventilation? } \\
\text { Have you suffered economically as a }\end{array}$ & 10 & 10 & 0 & 1 & 1 & 0 & 2 & 0 & 5 & 0 & 2 & 5 & 0 & 1 \\
\hline $\begin{array}{l}\text { result of your relative being ventilated? } \\
\text { Have you lost employment as a } \\
\text { result of the ventilation? }\end{array}$ & $\begin{array}{l}8 \\
8\end{array}$ & 0 & 0 & 13 & $\begin{array}{l}1 \\
1\end{array}$ & 0 & 2 & $\begin{array}{l}0 \\
1\end{array}$ & 1 & 0 & & & & \\
\hline $\begin{array}{l}\text { Has the personality of the } \\
\text { patient deteriorated? }\end{array}$ & 6 & 13 & 0 & 2 & 2 & 1 & 0 & 1 & 3 & 1 & 2 & 1 & 0 & 5 \\
\hline
\end{tabular}


if the decision to ventilate had not been taken. Five of these marriages existed at the time of injury. All were apparently stable at this stage, and all the wives were initially in favour of ventilation.

\section{Discussion}

Only a tetraplegic person understands what it is like to have tetraplegia and only relatives who care for them permanently may claim to understand the full burden of support required. The physician may know all about tetraplegia but cannot appreciate its reality and therefore cannot apply appropriately the principle of "doing to others as he would have them do to him" in deciding whether to give ventilation to a highly tetraplegic patient or allow him or her to die. Uncertainty as to the ultimate neurological outcome is not a satisfactory reason for ventilation, as no patients in this study had any appreciable neurological improvement.

The initial response of many clinicians to the disaster of sudden tetraplegia in a young person who was previously vigorous is to consider that such a person is better dead, from both the patient's and the family's point of view. The pathophysiology of tetraplegia may generate changes, which if not interrupted by artificial ventilation would result in cardiac or respiratory arrest and death. The temptation to allow nature to take its course is strong. The results of this study indicate that this approach is not what the patients and most of their caring relatives would support, unless perhaps appreciable brain damage had also occurred.

Outcome as defined was unfavourable in 16 cases. Since for almost half of the patients ventilation was not initiated until over 24 hours after injury, we attempted to determine whether any preinjury factor or combination of factors was associated with poor outcome, thereby hoping to establish a selective policy of ventilation. No combination of factors existing before the injury was invariably associated with poor outcome and good outcome was sometimes unexpectedly found.

Few would argue that it is unethical to allow any patient to die, whatever the circumstances. Ideally, the patient should make the decision whether he receives ventilation or is allowed to die. This, however, usually is not feasible because it is impossible for a newly injured person to appreciate the global implications of tetraplegia. Similarly, the relatives cannot be burdened with the responsibility for the decision. The view expressed by two thirds of the patients that the patient should help to make the decision usually arose from the realisation that if they had been admitted elsewhere they might have been allowed to die. The patient and family must be fully informed and their views taken into account.

A more difficult dilemma may arise during the early stages after ventilation has been started when the patient requests to be allowed to die. Our experience indicates that these requests express unhappiness, uncertainty, and suffering more often than a positive wish for death, and in all such cases after a variable period the patient has stated that he was glad to be alive. The views of relatives may also change with time, though usually in the reverse direction. It is a moot point whether the patient's doctor or an ethical committee should make the decision regarding ventilation. Whoever makes it should also take some responsibility for ensuring that its consequences are adequately dealt with.

Clinicians are faced more and more with decisions on the allocation of resources. Resources are finite and are diminishing progressively in relative terms as new treatments are generated. The fact that a treatment is available and of clear benefit does not mean that it can, or should, be provided since such provision may reduce the range or quantity of treatments that is available to others. For tetraplegic patients who require ventilation the simplest and most economical solution is to allow them all to die. This would not only improve the activity analysis and performance indicators of the centre but would also liberate nursing and physiotherapy staff and resources for other patients. Effective use of resources implies that the best value for money is obtained. Distinguishing among different qualities of life, however, is almost impossible. Nevertheless, when caring relatives, especially parents, become unable to cope so more resources will be diverted from newly injured patients.
These include resources not only of the hospital but also of the community which now cannot provide the total support required, as evidenced by the disasters of the young wives with young children.

The results of this study suggest that all patients with spinal cord injuries who might require ventilation should be transferred to intensive care units in comprehensive centres for spinal cord injuries as soon as possible after injury. Firstly, several ventilator deaths followed inappropriate initial management elsewhere. The highest dissatisfaction rate among relatives was in this group. Secondly, though the proportion of ventilated patients is smaller in an intensive care unit for spinal injuries compared with a general unit, weaning may be prolonged and present different problems. Furthermore, most general intensive care units are unsuitable for the prolonged care of conscious patients. Therefore, expertise is best developed in a few centres only to achieve optimum results with the available resources. Thirdly, the decision to ventilate a patient with spinal cord injuries may result in lifelong burdens for the patient and family. Thus the person who takes this decision should be prepared to ensure that the support required can be established and maintained. Finally, what determines a successful outcome is providing total emotional, educational, and physical support, which therefore should be established at the earliest opportunity.

The results of this study indicate that patients whose spinal cords are damaged should be artificially ventilated if required, provided that this can be carried out well and in a specialised centre with the necessary support, especially when the caring relatives become unable to cope because of age or disability. For other groups of patients, with spina bifida, for example, there are similar dilemmas of management. It would be interesting to know the views of such patients and their caring relatives. Leo Tolstoy states in War and Peace that "the most difficult but the most essential thing is to love life, to love it even when one suffers because life is all." This challenging view merits further evaluation.

We thank the Reverend John Mahoney, lecturer in moral and pastoral theology, Heythrop College, University of London, for helpful comments and $\mathrm{Mr} \mathrm{P}$ Kilshawe and $\mathrm{Mr} \mathrm{M}$ Pickering of the medical illustration department, Royal Preston Hospital. Part of the contents of this paper were presented at the annual scientific meeting of the International Society of Paraplegia, Denver, USA, June 1984.

\section{References}

1 Splaingard ML, Frates RC, Harrison GM, Carter RE, Jefferson FS. Home positive pressure ventilation. Twenty years' experience. Chest 1983;84:376-82.

Donovan WH, Taylor N. Ventilatory assistance in quadriplegia. Arch Phys Med Rehabil 1973;54:485-8.

3 Glenn WL, Hogan JF, Phelps ML. Ventilatory support of the quadriplegic patient with respiratory paralysis by diaphragm pacing. Surg Clin North Am 1980;60:1055-78.

4 Gross D, Ladd HW, Riley EJ, Macklem PT, Grassino A. The effect of training on strength and endurance of the diaphragm in quadriplegia. Am $\mathcal{J}$ Med 1980;68:27-35.

5 Huldtgren AC, Fugl-Meyer AR, Jonasson E, Bake B. Ventilatory dysfunction and respiratory rehabilitation in post-traumatic quadriplegia. Eur $\mathcal{F}$ Respir $D$ is 1980;61:347-56.

(Accepted 29 fuly 1985)

What benefits and what hazards are there for a 24 year old white man, who jogs regularly, does not smoke, and is not obese, of going on a "mineral water only" starvation diet of up to 10 days?

Although fasting was and still is seen as a useful discipline among many religious sects, nutritionally the regimen in question would not confer any benefits. In a healthy subject starvation for short periods does not produce any lasting physiological effects, although the classic responses to starvation' - that is, protein catabolism and ketosis - would ensue after a day or so because the mineral water would contribute virtually no carbohydrate. The effects would therefore be unpleasant but not physiologically long lasting.-D A T SOUTHGATE, head, nutrition and food quality division, Food Research Institute, Norwich.

Keys AA, Brozek J, Henschel A, Mickelson D, Taylor HL. The biology of human starvation. Vol 1 Oxford: University of Minnesota and Oxford University Press, 1950. 